\title{
Exploring the New Foreign Language Teaching Mode in Chinese Middle School Based on Action-Oriented Approach: Taking the English Listening and Speaking Class as an Example
}

\author{
Pengfei Wang ${ }^{1, *}$ Aijie Diao ${ }^{2}$ \\ ${ }^{1}$ Beijing Language and Culture University, Haidian, Beijing 100083, China \\ ${ }^{2}$ Qingdao No.39 Middle School Shibei Campus, Qingdao, Shandong 266031, China \\ *Corresponding author. Email: wangpengfei080170127@126.com
}

\begin{abstract}
China's Education Modernization 2035 plans to "improve the cultivation process and innovation capability of the first-class talents as well as further open the education sector to the world", etc. However, the current English classroom teaching has certain obstacles to the cultivation and implementation of the English core literacy, which needs to be reformed. Therefore, it is urgent to reform and innovate the traditional teaching mode in China and explore a new one based on reality. Action-oriented approach, which is popular in Europe, has attracted attention. This "action-oriented" teaching mode is of great significance to improve the practical communicative competence of foreign language learners. This paper will firstly sort out the basic theory of action-oriented approach to foreign language teaching and its foreign language teaching mode with "action" as its core. Then, it will combine the "action-oriented" approach with foreign language teaching practice in China, taking the ninth grade English listening and speaking course of the People's Education Press Edition as an example to introduce and promote the teaching approach, aiming to inspire the reform of foreign language teaching in China.
\end{abstract}

Keywords: action-oriented approach to foreign language teaching, teaching mode, exploration, middle school

English, listening and speaking class

\section{New Requirements of Middle School English Teaching in New Era}

China's Education Modernization 2035[1] proposed that the overall goal of promoting education modernization is to make China a powerhouse in terms of education, human resources and talents, specifically, improving cultivation process and innovation capability of the first-class talents as well as further opening the education sector to the world, which puts forward higher and newer requirements for China's existing education goals and models.

Taking foreign language discipline as an example, compared with native language learning, foreign language learning cultivates not only general language competence, but also cross-language and cross-cultural international communication competence, which is embodied in foreign language listening, speaking, reading and writing. Meanwhile, foreign language learning competence is not a general learning ability, but to learn another language on the basis of mother tongue. The English Syllabus For Full-time Junior High Schools In Nine-year Compulsory Education[2] clearly points out: "English curriculum in compulsory education stage should implement the policy of all-round development of morality, intelligence and physique. Gear education to the needs of modernization, the world and the future, focus on cultivating students' innovative spirits and practical ability, and comprehensively promote quality education. Carry on the ideological and emotional education to students through the English curriculum, making them understand and respect the outstanding cultural traditions of other countries and nations, understand and love China's excellent cultural tradition; develop students' ability of active thinking, expand their cultural and scientific knowledge, enrich their cultural life experiences, and improve their ideological and moral cultivation, so that they can adapt to the needs of our society, economy, scientific and technological development and international exchanges. "Based on the requirements above, The English Curriculum Standard for Compulsory Education [3] specifically proposes five curriculum teaching objectives including language skills, language knowledge, affective attitude, learning strategies and cultural awareness, as follows in Figure 1: 


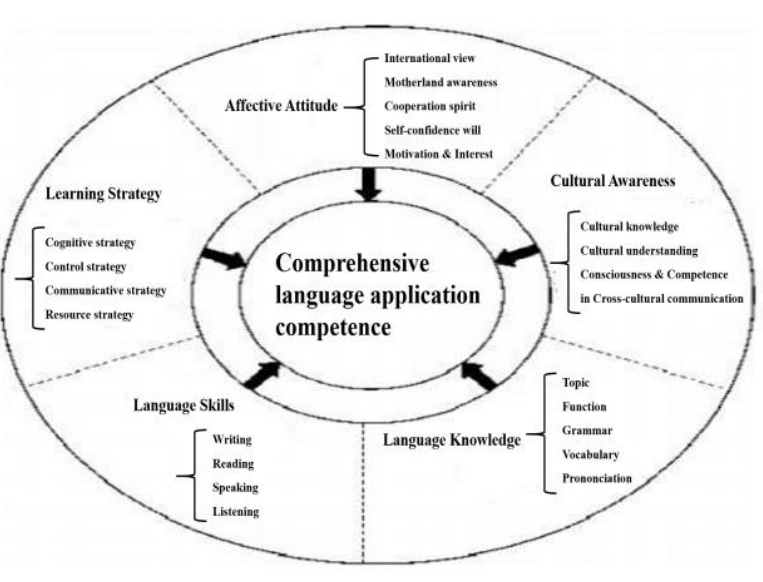

Figure 1: Teaching Objectives of English Curriculum for Compulsory Education(Cited from: Shu Dingfang[4], the authors translate)

It can be seen that the process of students' foreign language learning or foreign cultural knowledge acquired by language learning are additional channels to improve their comprehensive quality, which is a kind of "synergistic" supplement to the cultivation of students' comprehensive quality. That is to say, "while cultivating comprehensive language skills, it is necessary to emphasize the cultivation of thinking and innovation ability, strengthen the training of writing ability, increase the reading of classics, pay attention to the expansion of international vision, and focus on the comparison and understanding of Chinese and western cultures."[4] Therefore, English teaching should highlight "foreign language", "international communication ability", "international vision" and "crosscultural", and promote the improvement of "thinking quality" in the collision and comparison of different thinking patterns between China and the west.

Meanwhile, with the proposal of "core literacy of Chinese students' development", it is an important measure of taking high moral values establishment and people cultivation as the fundamental task to cultivate "well-rounded people" as the core so as to adapt to the trend of world education reform and development, and to enhance the international competitiveness of China's education. To implement these requirements, the newly revised The Ordinary High School English Curriculum Standards (2017 edition)[5] pointed out: "In order to reach the overall goal, English curriculum will set to cultivate and develop students' foreign language subject core literacy as its specific goal, aiming to cultivate and develop students' 'language ability', 'culture consciousness', 'thinking quality' and 'learning ability"'. At the same time, the Curriculum Standard pointed out that the core literacy of foreign language discipline includes knowledge and skills, processes and approaches, and affective attitudes and values education, which has a clear connotation of education and a certain level of performance that should be achieved, forming a collaborative relationship of mutual penetration, integration, interaction and common development.
Middle school English teaching in the new era and new situation needs higher requirements in teaching objectives and classroom teaching modes, requiring the core literacy including language competence, cross-cultural communication competence and other comprehensive abilities to be taken as the teaching objectives of English displine. How is the implementation of the core literacy of middle school English? Does current English teaching adapt to the cultivation and implementation of the core literacy of English displine? This paper will sort this problem out.

\section{THE CURRENT SITUATION OF CORE LITERACY OF ENGLISH DISCIPLINEIMPLEMENTATION IN CHINESE MIDDLE SCHOOLS}

In March 2014, the Ministry of Education of China put forward the "core literacy of Chinese students' development"[6], which is regarded as the critical step to promote curriculum reform, and relies on the education and teaching of various disciplines in the elementary education stage to achieve the cultivation of core literacy. Therefore, at the stage of elementary education, all disciplines should serve the development for students' core literacy, and help students with key competences and essential qualities as well as derive specific concepts of core literacy for all disciplines[7].

As for English discipline, after fully drawing on the experience of other countries in the cultivation of core literacy and combining with the characteristics of English discipline itself, the authors believe that the core literacy of English discipline should be based on the competence to use language and symbols for international and cross-cultural communication. At present, with the deepening of globalization, it is urgent to promote the establishment of a win-win cooperation for "community of human destiny". The talents needed by the society are bound to face more international and cross-cultural exchanges, and they are supposed to have stronger cross-cultural communicative competence and more abundant professional knowledge. Therefore, in the process of English teaching, we should change the curricular objectives from cultivating students' language use competence to their core literacy in crosscultural communication competence, global awareness, international understanding and information technology. English classroom teaching is gradually to become a process to develop students' thinking, broaden their horizons of knowledge and enrich their life experience as well as improve their humanistic quality [8]. Consequently, English learning is not only a process of mastering another communication tool, but also an important access for students to engage themselves with other cultures and form cross-cultural awareness and competence. It is also a process to promote the further development of students' thinking. In other words, English discipline has dual attributes of "instrumentality" and "humanism"[9].

But the implementation of core literacy, in some aspects, is also unsatisfactory. Recently, the OECD (Organisation for Economic Cooperation and Development) released its 
report on "TALIS (International Survey of Teachers' Teaching) 2018" in Paris. The report data show that teachers in our country have a high social identity and teaching efficiency, but there are still differences between the average value of OECD and their cultivation of students' core literacy, from which we can see there is still potential to improve the index closely related to students' core literacy[10]. To find out the reasons, it is urgent to be aware that there are still some problems in the current teaching, which hinder the implementation of disciplines' core literacy. For English, there are mainly three aspects involved. Firstly, the dislocation of discipline orientation. On the one hand, examination-oriented teaching and learning are still deeply rooted to a large extent in China. On the other hand, the understanding of the dual attributes of instrumentality and humanism of English in the new era is too insufficient to put into practice. Secondly, teachers find it is arduous to change their concepts. They stress "teaching" rather than "learning" and follow the concept of "teacher-centered", contrary to the goal of "studentscentered" and fully cultivating their core literacy. Thirdly, there is a lack of innovation in teaching mode, which is manifested in the superficial and seriously stylized classroom teaching, insufficiency of integration in fragmented teaching content, trouble in forming the competence, ignorance in creating theme situation and the deep exploration of the theme significance which has resulted in a lack of training in thinking[8]. Therefore, it is urgent to find a new way to meet the requirements for students' core literacy in English discipline and to innovate teaching approaches from guiding ideology to specific implementation path in an all-round way.

During the study in France, the authors were fortunate to have access to the "action-oriented" foreign language teaching approach which is popular in Europe. Through indepth research and continuous discussion with French experts in foreign language teaching and attending many long follow-up classes, the authors got great inspiration from this teaching approach. It is generally believed that the "action-oriented" foreign language teaching approach is suitable to be introduced to the English teaching in middle school classrooms in China. There is no doubt that it will certainly contribute to the cultivation of core literacy of English discipline and have the opportunity to take root firmly in China. In the following chapters, the paper will introduce the basic theory and characteristics of actionoriented foreign language teaching approach.

\section{3. "ACTION-ORIENTED” FOREIGN LANGUAGE TEACHING AND ITS CHARACTERISTICS IN PRACTICE}

The "action-oriented" foreign language teaching embodies the new orientation of foreign language learning in Europe. They believe that the purpose of learning a foreign language is not to learn the language itself, but to "integrate into a different community and become its member as far as possible"[11]. Obviously, this is very similar to the goal mentioned above of cultivating students' core literacy in
English teaching during the new period in China. In order to achieve this goal, action-oriented teaching creatively puts forward that "learning a foreign language means preparing to use it actively for communication" and "communication and learning will be achieved by completing tasks"[11]. Language users and learners are first identified as participants in social practice. In a specific area of social action, tasks, including language activities, are accomplished based on certain conditions and circumstances. The so-called "action" refers to the ability of one or more behaviour subjects to strategically use their capability of mastering to achieve a given goal. This is called an action, or a "mission"[11]. At the same time, the completion of an "action" is also a process of opening and innovation. Language users and learners develop their comprehensive competence, especially their competence to use language to communicate[11].

Based on what has been discussed above, the actionoriented approach requires teachers to design action plans according to teaching objectives and students' language proficiency level before class. Teachers have to organize students to participate in actions purposefully according to the action plan. Estelle Riquois, a pedagogist at the Fifth University of Paris in France, divides the design of action plan into three parts: action reference, action arrangement and action presupposition. Seven critical steps are listed as below in Table 1[12]:

Table 1: Specific critical steps in action plan design

\begin{tabular}{|l|l|}
\hline \multirow{4}{*}{ Action reference } & $\begin{array}{l}\text { Refer to the language } \\
\text { competence level } \\
\text { (Common CEFR } \\
\text { Framework of Reference for } \\
\text { Languages) }\end{array}$ \\
\cline { 2 - 2 } & \begin{tabular}{l} 
Determine teaching objectives \\
\cline { 2 - 2 } Consider the learners' specific \\
needs
\end{tabular} \\
\hline $\begin{array}{l}\text { Action } \\
\text { arrangement }\end{array}$ & $\begin{array}{l}\text { Setting action "scenario" for } \\
\text { action subject }\end{array}$ \\
\hline \multirow{2}{*}{$\begin{array}{l}\text { Action } \\
\text { presupposition }\end{array}$} & $\begin{array}{l}\text { Presuppose the help needed } \\
\text { assuppose }\end{array}$ \\
\cline { 2 - 2 } &
\end{tabular}

It is worth mentioning that the teacher has always served as the paver of action and the collaborator of action subject throughout the whole process of the action plan. As Riquois[12] pointed out: "Action plan should meet the needs and identity of learners. With the help of action plan, teachers organize teaching to create a real interactive communication context for learners." After the action, the teacher evaluates the overall situation of the action and the participation of the learners, while the learners provide feedback including gains, shortcomings and suggestions. The authors tries to present the teaching mode of "action" as the core in graphic form based on the above contents: 


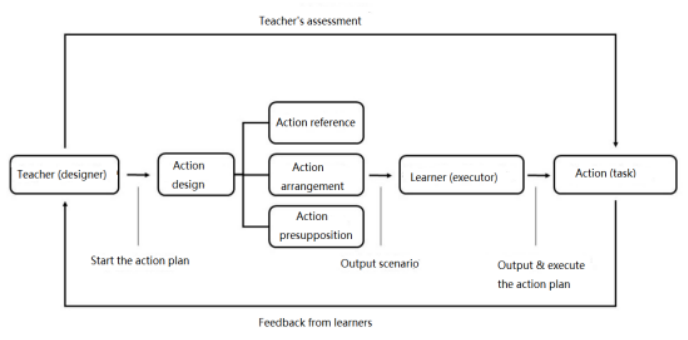

Figure 2: “Action-centered" Teaching Mode

In order to understand Riquois' presupposition of action plan as three parts and seven critical steps included and in combination with the practice of English classroom teaching in French middle schools and the basic theory of "action-oriented" teaching approach, the detailed explanations of the seven critical steps are listed as follows:

\section{- Refer to the language competence level in CEFR}

The CEFR divides the group of foreign language learners into six grades (from A1 to $\mathrm{C} 2$ ) according to their comprehensive level. The arrangement of courses and the design of action plans should adhere to the learners' foreign language level. It is worth mentioning that in order to make the corresponding courses match with the actual level of the students better. French foreign language teaching will test the students' level before teaching so as to determine the students' corresponding level of competence and match the appropriate courses accordingly.

\section{- Determine teaching objectives}

Action-oriented teaching mode emphasizes the cultivation of authentic communicative competence. It requires to take the three levels of teaching including "knowing", "doing" and "being" as the three objectives of teaching[13]. The goal of "knowing" mainly focuses on the acquisition of language knowledge, including the most basic ability of listening, speaking, reading and writing. The goal of "doing" focuses on language use, which achieves certain results or completes an action with language. It is similar to the idea of "acting by using words" and "acting guided by words" from the view of pragmatics. "Being" is the closest to the goal of "integrate into a different community and become its member as far as possible" in action-oriented teaching mode, including interpersonal communication, culture, social conventions, value system and so on. It is not difficult to see that the goal of "being" is the closest to the real world and it is ultimate goal of foreign language teaching.

- Consider the learners' specific needs

The learning needs for foreign language learners are divided into four categories: interpersonal communication competence, academic competence, social affairs handling competence and professional competence according to CEFR and the specific requirements of action-oriented teaching mode. Language acquisition is no longer regarded as the result of foreign language learning, but as a tool and approach to meet the needs of learners for various abilities. Therefore, the above four competences are based on language acquisition. As the name implies, interpersonal competence refers to the ability to engage in conversation with others. Academic competence refers to the ability to use language for academic activities, including attending seminars and making academic speeches, etc.. Social affairs handling competence includes the necessary language skills to survive in foreign language communities, such as handling various formalities, opening various services, etc.. Professional competence is the necessary language competence in work.

\section{- Determine the form of the task}

The so-called "task form" refers to how to carry out an action. The task initiated by action-oriented teaching mode is "chains of tasks" composed of several stages of tasks. The stage task is the necessary preparation and step of the final task. In the meantime, task of each stage is independent with its own complete form and target of language acquisition. Taking France as an example, English teaching in middle schools divides tasks into three stages: initial task, intermediate task and final task. Initial task, which is also known as "preparatory task", helps students prepare for follow-up tasks, such as vocabulary, sentence patterns, cultural knowledge, etc. This part consists of two channels: "self-preparation" and "assistance preparation". Selfpreparation means that learners complete preparations on their own according to their own ability and situation, while "assistance preparation" is related to another step of action design, which is "presupposition of the help needed by action subjects".. Teachers prepare the key points of knowledge that the learners need to master and strengthen in advance according to the learner's knowledge level and learning difficulties to assist the learners in preparation. Intermediate task, which is also known as "transitional task", refers to the fact that the learner completes some relatively simple output tasks on the basis of the initial task, while paving the way for the completion of the final task, such as make a summary on the given materials, elaborating positive and negative opinions on the given debate, etc. The final task refers to the implementation of the action plan designed in the earlier stage. It is not only the final product of action-oriented teaching, but also the concentrated reflection of teaching objectives. In terms of specific task forms, it is unnecessary for the three tasks to be a certain form but can be diverse such as spoken, written or even a combination of multiple forms.

\section{- Setting action "scenario" for action subject}

The so-called action "scenario" is to "simulate" the communication situation and tasks of the real world in the classroom teaching environment. Macroscopically speaking, it is an important step between "action design" and "action implementation", and it is also an important link between teachers and learners to establish a teaching relationship based on action[14]. Scenario is also an important guarantee for teaching optimization. Teachers help learners design and produce the final action plan based on scenario so as to establish learners' dominant position in foreign language teaching and improve their competences. The scenario setting is the core among the seven steps. Logically speaking, it directly transits the action from the design level to the implementation level. In content, scenario is similar to the "outline" of the final output action plan, and determines the required materials for the action as 
well as the goals and requirements to be achieved. Later, learners complete the action plan arrangement independently according to the scenario, while teachers only help the learners from the side but do not interfere too much in the learners' plan arrangement. To be a qualified "assistant" is also a higher requirement for teachers. Therefore, in specific operations, teachers should be allowed to carry out gradual identity transformation from "director" to "guide", and then to "assistant" [14].

\section{- Presuppose the help needed}

As an "assistant", teachers must have the ability to anticipate the problems that the action subjects may encounter in the process of planning and implementing action plans, and provide necessary help needed. In particular, instead of directly informing action subjects of solutions, teachers only provide knowledge to help action subjects solve problems and complete their actions while action subjects have to find solutions by themselves. This kind of help can be divided into the help in the preparation stage and in the action stage. Help in the preparatory stage is the help mentioned in the "Initial Task" above. The help in the action stage refers to the process from the scenario to the output of the action plan then to the implementation. It is certain that teachers shall not provide too much help to affect learners' ability improvement through action.

\section{- Presuppose post-action assessment}

One of the difficulties of action-oriented teaching mode is the accessment of "action" and "competence" based on action. French scholars put forward three principles for the assessment on action-oriented teaching mode accordingly: First, the assessment should focus on communicative competence, including language competence for the sake of improving communicative competence. Second, the assessment should adhere to the unity of "individual assessment" and "collaborative assessment", paying attention to both learners' individual and collaborative competence at the same time. Third, assessment should be based on the action output of task [15]. Based on these principles, the assessment should focus on four aspects which are language competence (master language knowledge, cultivate listening, speaking, reading and writing ability), application competence (ability to accomplish various kinds of action tasks), communicative competence (ability to cooperate, communicate and integrate with others) and other abilities (ability of learners in action such as drawing, computer capacity, etc.). Of course, there are different requirements for these four kinds of competences in the assessment. Generally speaking, learners are required to master language competence, strive to improve their application competence, cultivate communicative competence constantly, and encourage the development of other abilities actively.

Based on the above-mentioned teaching modes and specific steps, foreign language teachers can apply action-oriented teaching mode to teaching practice and establish a foreign language classroom with "action" as the core. In practice, France has established a complete set of "action-oriented" teaching mode, which covers a wide range, from primary school to university, from FLE to native foreign language teaching in France. The authors were impressed when attendeing a follow-up lesson named "Let's eat together" of English B1 level in French middle school. Teachers made full pre-class preparations on the contents and the needs of students in a wide range. They are similar to the preparation of textbooks and students in China but a sublimation than us to some extent, which we have been advocating all along. In the process of classroom tasks, "action" always speaks louder than others. It is not difficult to see that "action" is the core of "action-oriented" teaching mode, from which the students should "learn in action, in reflection and in cooperation"'[16]. Teachers should change from traditional knowledge infusion to guiding students' action and providing assistance to solve problems. In short, students learn and use their knowledge flexibly with teachers' guide and improve together[17]. In the specific teaching process, we have to take the "action" as the core to construct the teaching framework, and at the same time, put the action task throughout the teaching process.

\section{4. “ACTION-ORIENTED” FOREIGN LANGUAGE TEACHING AND ITS CHARACTERISTICS IN PRACTICE}

Through in-depth study and research on the French "actionoriented" approach to foreign language, the authors believe that it is an effective means and approach to combine the cultivation of language competence, cross-cultural communication competence and core literacy, and has important practical significance and great value to promote in English classroom teaching in China. To better promote the "action-oriented" teaching mode prevailing in the EU, and to combine this foreign language teaching theory with the English teaching practice in China's middle schools, the authors visited the middle schools, communicated with English teaching researchers and some excellent English teachers. With their support and guidance, the authors tentatively prepared a listening and speaking class for grade 9. With the support of the school leaders, the teacher (abbreviated as T), a senior teacher of a middle school in Qingdao, gave lectures, and received good results. The teaching steps are presented to provide reference for applying the "action-oriented" foreign language teaching approach into teaching practice in China's middle school foreign language classes and to enlighten the teaching innovation of the majority of middle school foreign language teachers.

\subsection{Before class}

Complete the initial task, i.e., the preparatory task. The initial task (preparatory task) consists of two parts - "selfpreparation" and "assistance preparation". Self-preparation means that the students complete the preparation task by themselves according to their own proficiency and the requirements of the course content. Before class, students are prompted to try to complete relatively simple output tasks on the basis of completing the initial task, thus paving the way for the completion of the final task. Assistance 
preparation is that teachers prepare some knowledge points that need to be mastered and strengthened for students in advance according to the students' knowledge level and the key points as well as difficult points in this lesson. Teachers anticipate and complete the assistance tasks that students may need in learning according to their own experience and understanding of teaching materials.

(1) Students' "self-preparation" tasks

(1) Students should preview the new words in this lesson and learn the sentence patterns "be supposed to" and "be expected to".

(2) Search the etiquette of people meeting for the first time on the Internet, which you focus on, make flashcards and prepare to share with the members in the same group.

(2) Teacher's “assistance preparation"tasks

(1) The teacher makes a video about a tour guide of a travel agency welcoming foreign tourists at the airport. The video shows the etiquette of the tour guide's first meeting with tourists from different countries (the countries involved are shown in textbook 1a).

(2) Be prepared for the difficulties students may encounter in the self-preparation process. For example, prepare for the teaching and practice of sentence patterns "be supposed to" and "be expected to" and the in-depth understanding of specific words.

(3) What's collected by students after searching the etiquette of people's first meeting online (i.e. self-preparation task (2)) may not be limited to the countries listed in the textbook. Teachers should make extensive preparations to meet the needs of other countries that students may know of.

\subsection{During class}

Step 1: Warm-up and lead in

$\mathrm{T}$ : What are people supposed to do when they meet for the first time?

People in different countries greet each other differently

S: Answer the teacher's questions

Teacher's Blackboard Writing:

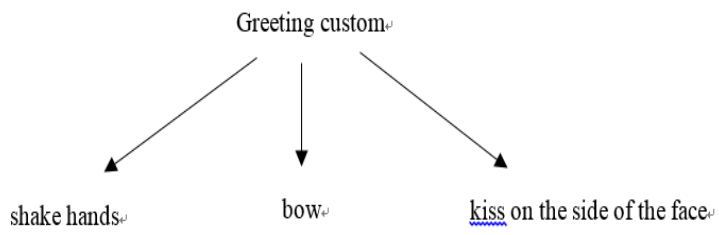

(1) The teacher plays the video prepared before class (i.e. the video made in assistance preparation tasks), leads the students to observe and answer "What do they do when they meet for the first time?" and let them guess "Which country do the guests come from?"

(2)Finish 1a \& 1b

Step 2: Practice (Finish 1c)

(1) Students communicate inside the group using their flashcards (i.e. self-preparation task (2)) and drill with 1c sentence pattern written in the flashcards - S1: "What are people in ...supposed to do?"S2: "They are supposed to ..."

(2) Teachers and students both get involved in the action, learn in action, and consolidate what they have learned in action.

The teacher prepares some flashcards with country names on. The students come to the stage in pairs and the teacher pastes the cards on their chest (The names on the card are covered). The students perform the dialogue based on their guess. After the performance, the teacher removes the cover of the cards. The students' dialogue performance may conform to the meeting etiquette of the countries marked on the cards. If not, the students will perform the dialogue again according to the country name shown on the cards. Activities 2a-2c

(1) Guide the students to listen to the tape in Section $2 \mathrm{a}$ carefully, which is "Maria is an exchange student. Last night she had dinner at an American friend's house, she made some mistakes." After listening, choose Maria's wrong behaviour. Section $2 \mathrm{~b}$ prompts the students to pay attention to Maria's specific wrong behavior when listening to the tape, and fill in the blanks in Section $2 b$ after listening. (2) From but beyond textbooks. The teacher raises supplementary questions to consolidate listening content.

- How many mistakes did Maria make?

- When did she arrive?

- Why did she arrive late?

(3) Summarize the cultural customs learned and complete the form:

\begin{tabular}{|c|c|c|}
\hline $\begin{array}{c}\text { Ideas and } \\
\text { customs about }\end{array}$ & $\begin{array}{c}\text { In Maria's } \\
\text { country }\end{array}$ & In America \\
\hline Time & $\begin{array}{c}\text { People are } \\
\text { supposed to } \\
\text { arrive late. }\end{array}$ & $\begin{array}{c}\text { People are } \\
\text { supposed to } \\
\text { arrive on time. }\end{array}$ \\
\hline Greetings & $\begin{array}{c}\text { People are } \\
\text { supposed to kiss } \\
\text { when they meet } \\
\text { for the first } \\
\text { time. }\end{array}$ & $\begin{array}{c}\text { People are } \\
\text { supposed to } \\
\text { shake hands } \\
\text { when they meet. }\end{array}$ \\
\hline Dressing & $\begin{array}{c}\text { People are } \\
\text { supposed to } \\
\text { wear a suit or } \\
\text { fancy dress to } \\
\text { the party. }\end{array}$ & $\begin{array}{c}\text { People are } \\
\text { supposed to } \\
\text { wear a T-shirt } \\
\text { and jeans to an } \\
\text { outdoor party. }\end{array}$ \\
\hline
\end{tabular}

(4)Language output based on the listening content in $2 \mathrm{a} \&$ $2 \mathrm{~b}$. Combine specific information in the form above or $2 \mathrm{a}$ $\& 2 b$ and make a role-play. Role-play a conversation between Maria and Dan (Finish 2c).

Step 3: Discussion

-Based on the passage, talk about the question "which country's etiquette do you like best?".

-Analyze the reasons why there are so many differences among different countries?

-Take our own country as an example, can etiquette change in a country over a century? 
Guide students to think and realize that civilization is like water, nourishing all without a sound. There is no conflict among civilizations. We should learn to respect cultural differences and appreciate colorful civilizations together. Therefore, we realize that civilization is colorful due to communication and rich due to mutual learning. Now we should earnestly learn foreign languages and lay a foundation for future cross-cultural communication.

\subsection{After class}

(1) T: dear students, we have been assigned to train the employees who plan to go abroad of a large enterprise in etiquette. They will visit Brazil, South Korea, Mexico and France. Please choose a country for your a group, combine with the learning content of this lesson, expand appropriately, and write the etiquette training manual for staff going abroad. Please upload the manual to WeChat group of our class before 20:00 pm tonight. The teacher will correct them one by one and send the corrected manuals to WeChat group. Please use the knowledge you have learned in the computer science class to make a brochure of etiquette for personnel going abroad. I hope the brochure can be beautiful and practical with texts and graphics. In addition, the teacher wrote a training manual for personnel going abroad for an enterprise last year. Now I will send the mind map of this manual to you for reference.

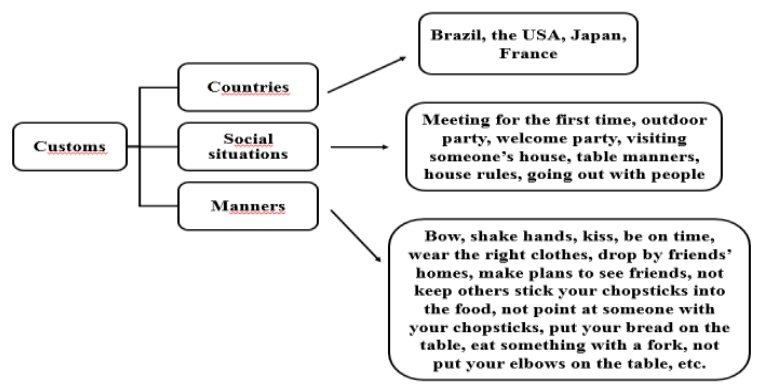

Figure 3: Mind map of the activity

(2) After class assessment and feedback

Teacher's reflection: Are the assistance preparation tasks completed? What are the tasks that the teacher did not presuppose before class? Are the communication and learned realized through action? Have the expected teaching results been achieved?

Teacher's reflection:

\begin{tabular}{|c|c|c|c|}
\hline \multicolumn{4}{|c|}{ Reflexion of my job } \\
\hline $\begin{array}{c}\text { What } \\
\text { worked } \\
\text { well }\end{array}$ & $\begin{array}{c}\text { What didn't } \\
\text { work well }\end{array}$ & $\begin{array}{c}\text { How to } \\
\text { improve }\end{array}$ & Advice \\
\hline & & & \\
& & & \\
\hline
\end{tabular}

Student feedback:

Student feedback:
\begin{tabular}{|c|c|c|}
\hline Greatest gain & Unsolved puzzle & $\begin{array}{c}\text { Advice to the } \\
\text { teacher }\end{array}$ \\
\hline & & \\
& & \\
\hline
\end{tabular}

\section{CONCLUSION}

This paper has introduced the theoretical basis of the "action-oriented" approach of foreign language teaching prevailing in Europe and the foreign language teaching mode with the "action" as its core. Based on the English teaching practice in Chinese middle schools, the authors tried to apply the "action-oriented" approach of foreign language teaching to the English listening and speaking class in ninth grade of PEP. The authors hope that this attempt can play a role of "casting bricks and attracting jade", so that great number of researchers in the field of basic foreign language teaching can pay more attention to the "action-oriented" approach of foreign language teaching and to explore foreign language teaching theories and teaching framework with better effects. And finally, we wish our attempts and contributions will help to realize the training goal of core literacy in the subject teaching in the basic education stage of China and make unremitting efforts to realize the overall teaching goals and requirements set forth in China's Education Modernization 2035.

\section{ACKNOWLEDGMENT}

This work was funded by 2017 China-France "CAI Yuanpei" exchange and cooperation programme (No.201700260136) of China Scholarship Council.

\section{REFERENCES}

[1] The Central Committee of the Communist Party of China \& the State Council of China. China education modernization 2035 framework [EB/OL]. 2019-02-23 [2019-05-25]. http://www.gov.cn/zhengce/201902/23/content_5367987.htm.

[2] English syllabus for nine-year compulsory education[J]. Standards For Foreign Language Learning. 2000(2).

[3] China's Minister of Education. English curriculum standard for compulsory education[S]. Beijing: Beijing Normal University Publishing House,2011.

[4] Shu, D. Some thoughts on key competencies for English as a foreign language in Chinese high schools[J]. Shandong Foreign Language Teaching. 2017(2) :35-41. 
teaching and learning in Europe and its inspirations[J]. Journal of Sichuan International Studies University. 2008(1) :129-133.

[17] Wang, P. “Action-oriented approach": Referential meaning to China's foreign language teaching[J]. English Teaching and Research Notes. 2017(1) :16-20. virtue and fostering people[Z]. 2014-03-30 [2019-05-25]. http://old.moe.gov.cn/publicfiles/business/htmlfiles/mo e/s7054/201404/167226.html.

[7] Cheng, X. \& Zhao S. On students' key competency in English as a foreign language[J]. Curriculum, Teaching Material and Method.2016(5): 79-86.

[8] Wang, Q. From comprehensive language application ability to English discipline core literacy-new challenges in high school English curricular reform[J]. English Teachers. 2015(16): 6-7.

[9] Cheng, X. Key competences in English and their assessment[J]. China Examinations. 2017(5):7-14.

[10] OECD. TALIS 2018 Results (Volume I): Teachers and School Leaders as Lifelong Learners[R], TALIS, OECD Publishing, Paris. 2019-06-19 [2019-06-20] https://doi.org/10.1787/1d0bc92a-en.

[11] European Council. "Common European Framework of Reference for Languages: Learning, Teaching, Assessment"[M].(J.Liu \&R. Fu, Trans. ). Peking: Foreign Language Teaching and Research Press, 2008

[12] Riquois, E. L'approche actionnelle[A]. In $\mathrm{La}$ perspective actionnelle, toujours d'actualité(?!)[C/OL]. Lyon :Le GFEN. 2015-03-21 [2019-05-25]. http://gfen.langues.free.fr/activites.html.

[13] Holmes, P. \& O'Neill, G. Developing and evaluating intercultural competence :Ethnographies of intercultural encounters[J]. International Journal of Intercultural Relations.2012(5) :707-718.

[14] Bourguignon, C. Apprendre et enseigner les langues dans la perspective actionnelle: le scénario d'apprentissage-action[J/OL]. Les langues modernes. 2007 [2019-05-25]. http://www.aplvlanguesmodernes.org/spip.php?article865.

[15] Puren, C. Plaidoyer en faveur de la réforme du collège[EB/OL]. 2015-05-17 [2019-05-25]. https://www.christianpuren.com/2015/05/17/plaidoyeren-faveur-de-la-réforme-du-collège.

[16] $\mathrm{Pu}, \mathrm{Z}$. "action" And foreigh langauge teaching/learning: the changing of beliefs in language 